\title{
Methimazole-Induced Febrile Neutropenia
}

\author{
Behçet Varışlı', Sinan Yıldırım', Hatice Karaçam², Şehnaz Paker
}

'Department of Emergency Medicine, Çanakkale State Hospital, Çanakkale, Turkey

2Department of Emergency Medicine, Bağcllar Training and Research Hospital, Istanbul, Turkey

Cite this article as: Varışı B, Yıldırım S, Karaçam H, Paker Ş. Methimazole-Induced Febrile Neutropenia. J Emerg Med Case Rep 2018; 9: 13-5.

\begin{abstract}
Introduction: Antithyroid drugs (ATD) are commonly used for the treatment of thyrotoxicosis, particularly for the treatment of Grave's disease. Methimazole is the first line ATD. A major fatal adverse effect of ATDs, if unrecognized and not treated on time, is agranulocytosis, which is defined as an absolute neutrophil count of $<500 / \mu \mathrm{L}$. The incidence of ATD-induced agranulocytosis is $0.1 \%-0.3 \%$ (1). In this study, we report on a patient who developed granulocytopenic febrile neutropenia at 3 months after treatment with methimazole ( $5 \mathrm{mg}$ twice a day per os (BID PO)).

Case report: A 51-year-old female patient presented to the emergency department with complaints of fever, fatigue, and productive cough. Her body temperature was $38.5^{\circ} \mathrm{C}$; rales were heard on the mid and basal part of the left lung. Drug history revealed methimazole use (10 mg per day over the last 2 months). The WBC count was 1020/ $\mu \mathrm{L}$, and the neutrophil count was $200 / \mu \mathrm{L}$. The patients' baseline WBC differential count and immune status were normal. Following inpatient antibiotic treatment and discontinuation of methimazole, the patient became afebrile within 2 days. After 2 weeks of discontinuation of

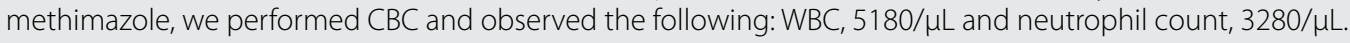

Conclusion: Patients visiting the emergency department with symptoms of a systemic infection and known to use ATDs should be thoroughly evaluated, and the possibility of drug-induced agranulocytosis developing because of the use of these medications should be considered. It is very important for emergency physicians to recognize this rare patient population and act in a timely manner.
\end{abstract}

Keywords: Methimazole, febrile neutropenia, agranulocytosis, antithyroid drugs, fever, emergency medicine

Received: 11.05.2017 Accepted: 02.08.2017

\section{Introduction}

Antithyroid drugs (ATD) are commonly used in the treatment of thyrotoxicosis, particularly in the treatment of Grave's disease. Methimazole is a first line ATD. Drug-induced agranulocytosis has been defined as an absolute neutrophil count of $<500 / \mu \mathrm{L}$, and it is a major fatal side effect of ATD if unrecognized and not treated on time. It is generally manifested within the first few weeks or months of treatment and is accompanied by fever and sore throat and other signs and symptoms that are related to a thyrotoxic state (tachycardia, tremor, anxiety, and pulsatile goiter). Incidence of ATD-induced agranulocytosis is $0.1 \%-0.3 \%$ (1). Febrile neutropenia ( $F N$ ) is defined as an oral temperature of $>38.3^{\circ} \mathrm{C}$ or two consecutive readings of $>38.0^{\circ} \mathrm{C}$ for $2 \mathrm{~h}$ and an absolute neutrophil count of $<0.5 \times 109 / /$ or expected to decrease $<0.5 \times 109 / \mathrm{l}(2)$. The patient population susceptible to ATD-induced agranulocytosis are explored by a number of genome-wide association studies that showed a strong association between ADT-induced agranulocytosis and single-nucleotide polymorphisms of HLA alleles HLA-b*38:02; HLA-drb1*08:03, which is more prevalent in the Asian population; and HLA-b*27:05 on chromosome 6, which is more prevalent in the Caucasian populations (4). Among ATDs, both propylthiouracil and methimazole may cause agranulocytosis. When ATD-induced agranulocytosis is observed, it is crucial to stop the treatment. In this study, we report on a pa- 
tient who developed granulocytopenic FN at the 3rd month after methimazole (5 mg BID PO) treatment.

\section{Case Report}

A 51-year-old female patient was admitted to the emergency department with complaints of fever, lethargy, fatigue, cough, and sputum production since the past 5 days. Her vital signs were as follows: arterial blood pressure, 90/60 mmhg; pulse, 110 beats/min; temperature, $38.5^{\circ} \mathrm{C}$; and respiratory rate, $20 / \mathrm{min}$. On physical examination, there were no other findings besides rales heard on the mid and basal part of the left lung. Her medical history revealed methimazole use of $10 \mathrm{mg}$ per day over the last 2 months for treatment of hyperthyroidism. Her laboratory findings were normal, except for WBC count of $1020 / \mu \mathrm{L}$ and a neutrophil count of $200 / \mu \mathrm{L}$. Her T3, T4, and TSH levels were normal (The following are the reference values for adult thyroid function test ordered commonly in Çanakkale State Hospital, T3: 3,80-6,40 pLU/L; T4: 7,86-14,40 pLU/L; TSH:0,34-5,60 $\mu \mathrm{LU} / \mathrm{L})$. Her posteroanterior chest radiograph showed pneumonic infiltrations in the mid and basal parts of the left lung. The patient was hospitalized with an initial diagnosis of FN, and informed consent was obtained from her. She was administered empirical broadspectrum antibiotics, and patient was admitted to a single- occupancy room and the number of visitors and staff who enter the patient's room was limited. She received intravenous levofloxacin (500 mg QD) and intravenous ceftriaxone (1 g BID). The patient had no history of smoking, alcohol consumption, or drug use. She had no previous record of hospital admission, trauma, or surgical interventions including splenectomy. In addition, there was no history of direct patient contact, infectious diseases, or malignancy or hypertension, diabetes, kidney disease, or other chronic diseases. The patient's baseline WBC differential count, which was conducted before the start of methimazole treatment, was in a normal range (WBC, $6920 / \mu \mathrm{L}$ and neutrophil count, 412/ $\mu \mathrm{L}$ ). We stopped methimazole treatment. Upon discontinuation of the medication, the patient became afebrile within 2 days. On discontinuation of methimazole for 2 weeks, we performed CBC and observed the following: WBC, 5180/ $\mu \mathrm{L}$ and neutrophil count, 3280/ $\mu \mathrm{L}$. Two days later, the patient was discharged from the hospital when her symptoms significantly improved. She was advised to follow-up with her endocrinologist.

\section{Discussion}

Hyperthyroidism is a common endocrine condition, and the mainstay of treatment has been ATD. Methimazole is the commonest ATD used, and it can cause fatal complications like agranulocytosis (0.1\%-0.3\%). Two major hypotheses for the pathophysiology of ATD-induced agranulocytosis are explained by Jing Yang and Jing Zhong et al (5) and include direct toxic effects and immunological reactions. As a genetic background of ADT-induced agranulocytosis, the following alleles were found to be associated: single-nucleotide polymorphisms of HLA alleles HLA-b*38:02; HLA-drb1*08:03, which is more prevalent in the Asian population, and HLA-b*27:05 on chromosome 6, which is more prevalent in the Caucasian population $(4,6,7)$.

Patients with ATD-induced agranulocytosis present with high fever and sore throat. FN is defined as an increase in temperature to $38.3^{\circ} \mathrm{C}$ on one occasion or having a temperature of $\geq 38.0^{\circ} \mathrm{C}$ for $1 \mathrm{~h}$. There have been a number of case reports published for ATD-induced agranulocytosis, but there have been quite a few (8) reports addressing FN. Our patient used methimazole (5 mg BID PO) for treatment of Grave's disease, and it was not until the 3rd month that systemic infection was diagnosed with a dramatic decrease in previously normal granulocyte count. On admission, her temperature was $38.5^{\circ} \mathrm{C}$, and lobar pneumonia was detected by physical and radiological examination. Her WBC count was $1-20 / \mu \mathrm{L}$ and neutrophil count was $200 / \mu \mathrm{L}$. The patient did not have a medical history of FN. The patient's baseline WBC differential count, which was conducted before the start of methimazole treatment, was in a normal range (WBC, 6920/ $\mu \mathrm{L}$ and neutrophil count, $412 / \mu \mathrm{L}$ ). All cases of neutropenia exhibiting pneumonia must be considered as patients with a high risk and in need of hospitalization (2). However, there is a low-risk group of FN cases (2) defined in the recent years, which can often be treated on an outpatient basis. In our case, the patient was hospitalized. We started empirical antibiotic treatment; the patient was administered intravenous broad-spectrum antibiotics: ceftriaxone (1 g BID) and levofloxacin (1 g QD). Following discontinuation of methimazole for 2 weeks, a complete cell count test was performed, and we observed improvement on CBC (WBC, $5180 / \mu \mathrm{L}$ and neutrophil count, 3280/ $\mathrm{LL}$ ). For the treatment of ATDinduced agranulocytosis, there have been several publications which report that the use of granulocyte colony-stimulating factor (G-CSF) promptly improves the granulocyte count and suggest that it should be included in the standard treatment protocol. However, there are other publications which find G-CSF ineffective in the treatment of severe FN $(2,4)$. In our case, G-CSF use was not employed; empirical antibiotherapy and termination of methimazole treatment were adequate in treating our patient.

\section{Conclusion}

The pathogenesis of ATD-induced agranulocytosis remains incompletely understood, but seems to involve multiple factors including direct toxic effects, immunological reactions, and genes. Because the occurrence of ATD-induced agranulocytosis is a serious adverse effect, before methimazole treatment commences, all patients must be warned, in writing, to seek medical advice and stop the medication if features suggesting agranulocytosis (fever, mouth ulcers, and sore throat) develop (3). Patients visiting the emergency department with symptoms of a systemic infection and known to use ATDs should be thoroughly evaluated; the possibility of drug-induced agranulocytosis developing because of the use of these medications should be considered. It is very important for emergency physicians to recognize this rare patient population and act in a timely manner.

Informed Consent: Written informed consent was obtained from the patient who participated in this study.

Peer-review: Externally peer-reviewed.

Author Contributions: Concept - B.V.; Design - S.Y., Ş.P.; Supervision - B.V.; Resources - S.P.; Materials - B.V.; Data Collection and/or Processing - B.V.; Analysis and/or Interpretation - B.V., H.K.; Literature Search - H.K.; Writing Manuscript - H.K.; Critical Review - B.V., H.K., S.Y. 
Acknowledgements: The authors would like to thank AP. Mehmet Akif Karamercan for revising the manuscript and references critically.

Conflict of Interest: No conflict of interest was declared by the authors.

Financial Disclosure: The authors declared that this study has received no financial support.

\section{References}

1. Melmed S, Polonsky KS, P. Larsen R, Kronenberg HM. Williams textbook of endocrinology. 13th edition. ed. Hyperthyroid Disorders, ed. T.F. Davies, P. Laurberg, and R.S. Bahn. 2016, Philadelphia, PA: Elsevier. xviii, 1916 pages.

2. Klastersky J, de Naurois J, Rolston K, Rapoport B, Maschmeyer G, Aapro $M$, et al. Management of febrile neutropaenia: ESMO Clinical Practice Guidelines. Ann Oncol 2016; 27(suppl 5): p. v111-v8. [CrossRef]

3. Weetman AP. The thyroid gland and disorders of thyroid function: Oxford Textbook of Medicine. Oxford University Press; 2010: 1826-44. [CrossRef]
4. Vicente N, Cardoso L, Barros L, Carrilho F. Antithyroid Drug-Induced Agranulocytosis: State of the Art on Diagnosis and Management. Drugs RD 2017; 17: 91-6. [CrossRef]

5. Yang J, Zhong J, Xiao XH, Zhou LZ, Chen YJ, Liu JH, et al. The relationship between bone marrow characteristics and the clinical prognosis of antithyroid drug-induced agranulocytosis. Endocr J 2013; 60: 185-9. [CrossRef]

6. Cheung $\mathrm{CL}$, Sing $\mathrm{CW}$, Tang CS, Cheng VK, Pirmohamed M, Choi CH, et al. HLA-B*38:02:01 predicts carbimazole/methimazole-induced agranulocytosis. Clin Pharmacol Ther 2016; 99: 555-61. [CrossRef]

7. Hallberg P, Eriksson N, Ibañez L, Bondon-Guitton E, Kreutz R, Carvajal A, et al. Genetic variants associated with antithyroid drug-induced agranulocytosis: a genome-wide association study in a European population. Lancet Diabetes Endocrinol 2016; 4: 507-16. [CrossRef]

8. Jabr Fl. Methimazole-induced severe febrile neutropenia responding to recombinant human granulocyte colony stimulating factor. South Med J 2008; 101: 665. [CrossRef] 